\title{
Hormonal Changes in the Menopause Transition
}

\author{
Henry G. Burger*, Emma C. Dudley ${ }^{\dagger}$, David M. Robertson*, and \\ LORRAINE DENNERSTEIN ${ }^{\dagger}$
}

*Prince Henry's Institute of Medical Research at Monash Medical Centre, Clayton, Victoria, Australia; 'Office for Gender and Health, Royal Melbourne Hospital, Parkville, Victoria, Australia

\begin{abstract}
The menopause is the permanent cessation of menstruation resulting from the loss of ovarian follicular activity. It is heralded by the menopausal transition, a period when the endocrine, biological, and clinical features of approaching menopause begin. A common initial marker is the onset of menstrual irregularity. The biology underlying the transition to menopause includes central neuroendocrine changes as well as changes within the ovary, the most striking of which is a profound decline in follicle numbers. Follicle-stimulating hormone (FSH) is an established indirect marker of follicular activity. In studies of groups of women, its concentration, particularly in the early follicular phase of the menstrual cycle, begins to increase some years before there are any clinical indications of approaching menopause. The rise in FSH is the result of declining levels of inhibin B (INH-B), a dimeric protein that reflects the fall in ovarian follicle numbers, with or without any change in the ability of the lining granulosa cells to secrete INH-B. Estradiol levels remain relatively unchanged or tend to rise with age until the onset of the transition and are usually well preserved until the late perimenopause, presumably in response to the elevated FSH levels. During the transition, hormone levels frequently vary markedly - hence, measures of FSH and estradiol are unreliable guides to menopausal status. Concentrations of testosterone have been reported to fall by about $50 \%$ during reproductive life, between the ages of 20 and 40. They change little during the transition and, after menopause, may even rise. Dehydroepiandrosterone (DHEA) and DHEAS, its sulphate, on the other hand, decline with age, without any specific influence of the menopause. Symptoms of the menopause can be interpreted as resulting primarily from the profound fall in estradiol, occurring over a 3- to 4-year period around final menses, a fall that presumably contributes importantly to the beginning, in the late perimenopause, of loss of bone mineral density.
\end{abstract}

\section{Introduction and Definitions}

The World Health Organization has defined the menopause as the permanent cessation of menstruation resulting from loss of ovarian follicular activity (World Health Organization, 1996). The perimenopause commences when the first features of approaching menopause begin until at least 1 year after final menstrual period (FMP). The term "menopausal transition" has been applied to that portion of the perimenopause that ends with the FMP. The median age of 
onset has been reported as between 45.5 and 47.5 years; the average duration is 4 years (Treloar, 1981; McKinlay et al., 1992). The incidence of dysfunctional uterine bleeding and hysterectomy are maximal during the menopausal transition and the incidence of symptoms is similar to that in early postmenopausal women (McKinlay et al., 1992; Dennerstein et al., 1993).

It is strongly recommended that the term perimenopause be used as indicated here and not applied loosely to women in their 40s and early 50s who continue to have regular menstrual cycles and no symptoms of approaching menopause. Studies of the hormonal changes during the perimenopause have been based on various experimental designs and definitions. In some instances, they have been recorded as a function of age with little attention to menstrual cycle status (Sherman et al., 1976). In the few longitudinal studies reported, the FMP has been used as a reference point, with hormonal changes described in terms of time intervals before and after that point (Metcalf et al., 1981; Longcope et al., 1986; Rannevik et al., 1986,1995). A few studies have reported hormone changes in relation to changes in menstrual cycle characteristics, such as the first selfreported change in the amount of menstrual flow, in the frequency of menstruation, or in the combination of changes in flow and frequency, an approach that has been adopted in the Melbourne Women's Midlife Health Project (Burger et al., 1995).

\section{Changes in the Pituitary-Ovarian Axis with Age in Regularly Cycling Women}

Although the changes that occur in the circulating concentrations of folliclestimulating hormone $(\mathrm{FSH})$, luteinizing hormone $(\mathrm{LH})$, estradiol $\left(\mathrm{E}_{2}\right)$, and progesterone $(\mathrm{P})$ during the normal menstrual cycle have been well known for several decades, it is only within the last 10 years that the changes in circulating inhibins have been documented (Groome et al., 1996). Relatively stable and low values for both $\mathrm{E}_{2}$ and inhibin A (INH-A) are found during the first half of the follicular phase of the cycle, followed by a rise to midcycle peaks approximately 24 hours before the ovulatory LH surge. The concentrations then fall and rise again to secondary peaks parallel to the peak in $\mathrm{P}$ secretion during the luteal phase. There is a subsequent fall in the circulating concentrations of all three hormones prior to the onset of menses. Inhibin B (INH-B), on the other hand, rises and falls closely parallel to the changes in FSH during the luteal-follicular transition and the early follicular phase. There is a midcycle peak but, during the luteal phase, INH-B concentrations decline to their lowest points in the cycle (Figure 1). The normal pattern of $\mathrm{E}_{2}$ and INH-A secretion is preserved when their concentrations are examined as a function of increasing age in regularly cycling women. For example, in a large cross-sectional study of women who ranged in age from 24-50 years (Lee et al., 1988), early follicular-phase concentrations of 

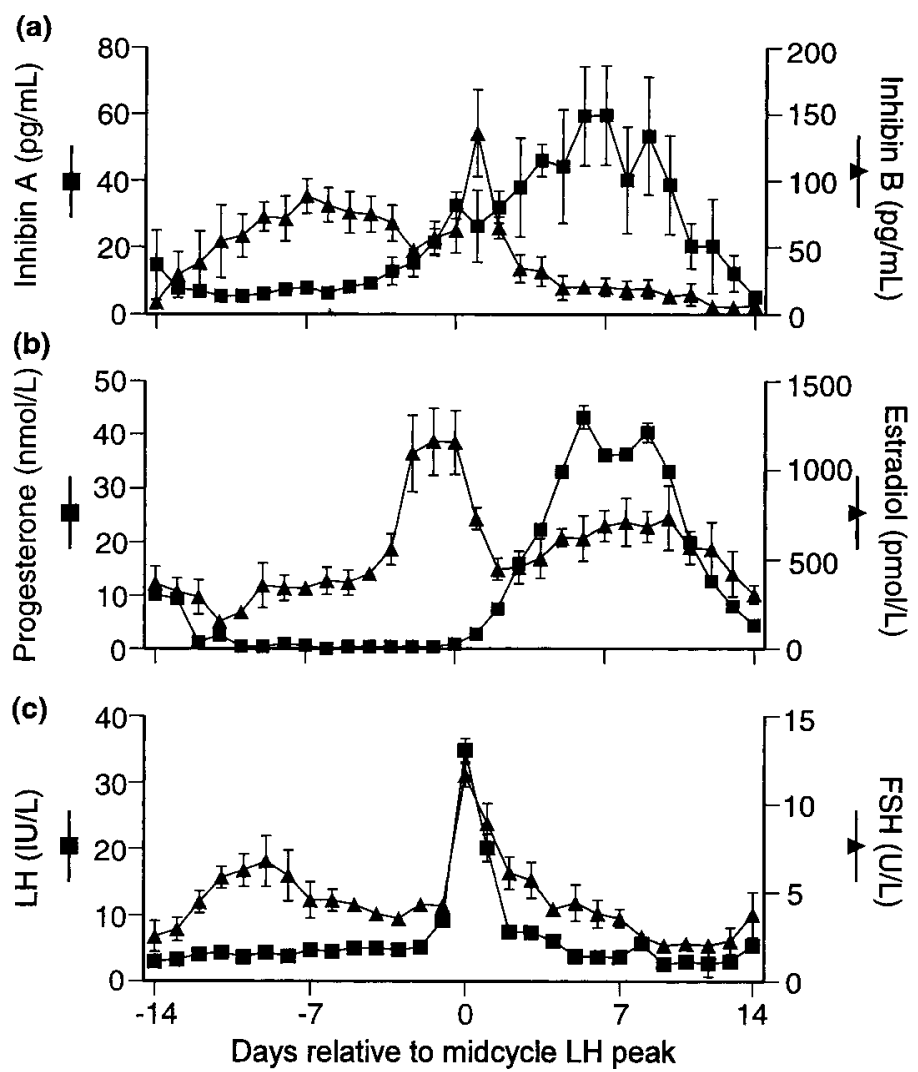

FIG. 1. Plasma concentrations of (a) inhibin A and inhibin B, (b) estradiol and progesterone, and (c) luteinizing hormone (LH) and follicle-stimulating hormone (FSH) during the menstrual cycle. Data displayed with respect to day of midcycle LH peak. [Adapted with permission from Groome NP, Illingworth PJ, O’Brien M, Rodger PAL, Rodger FE, Mather JR, McNeilly AS 1996 Measurement of dimeric inhibin B throughout the human menstrual cycle. J Clin Endocrinol Metab 81:1401-1405. Copyright The Endocrine Society.]

$\mathrm{E}_{2}$ tended to rise slightly in the oldest group of subjects, despite a progressive rise in FSH concentrations. In another study, older women were compared with a young control group and showed increased levels of urinary estrogens and a fall in urinary pregnandiol excretion in the luteal phase of the cycle, despite continued regular cyclicity (Santoro et al., 1996). The rise in serum FSH was accompanied by minimal, if any, changes in circulating LH. The most-plausible explanation for the monotropic rise in FSH was a decline in circulating INH concentrations with age. This was first indicated in a study by MacNaughton et al. (1992) in which single samples were taken in the early follicular phase of 
regularly cycling subjects and showed a rise in $\mathrm{FSH}$, no significant change in $\mathrm{LH}$, and a decline in the circulating concentrations of immunoreactive INH. That the rise in FSH actually was specifically related to a fall in the circulating concentrations of INH-B was shown by Klein et al. (1996), who compared a group of older ovulatory women, selected to have increased circulating concentrations of FSH, with a group of young, regularly cycling subjects. Serum FSH was significantly elevated as expected and INH-B levels were significantly lower in the older women than in the younger women, while INH-A was unchanged and $\mathrm{E}_{2}$ was actually higher in the older women (Figure 2).

The present authors have more-recently confirmed the progressive increase in circulating FSH levels with increasing age in regularly cycling women, though the rise in FSH was seen predominantly in some women over the age of 40 (Burger et al., 2000b) (Figure 3). A clear inverse relationship between INH-B and FSH in women over the age of 40 was demonstrated in that study (Figure 4).

Substantial evidence exists that the circulating concentrations of INH-A and INH-B are under differential control. INH-A, together with $\mathrm{E}_{2}$, is derived
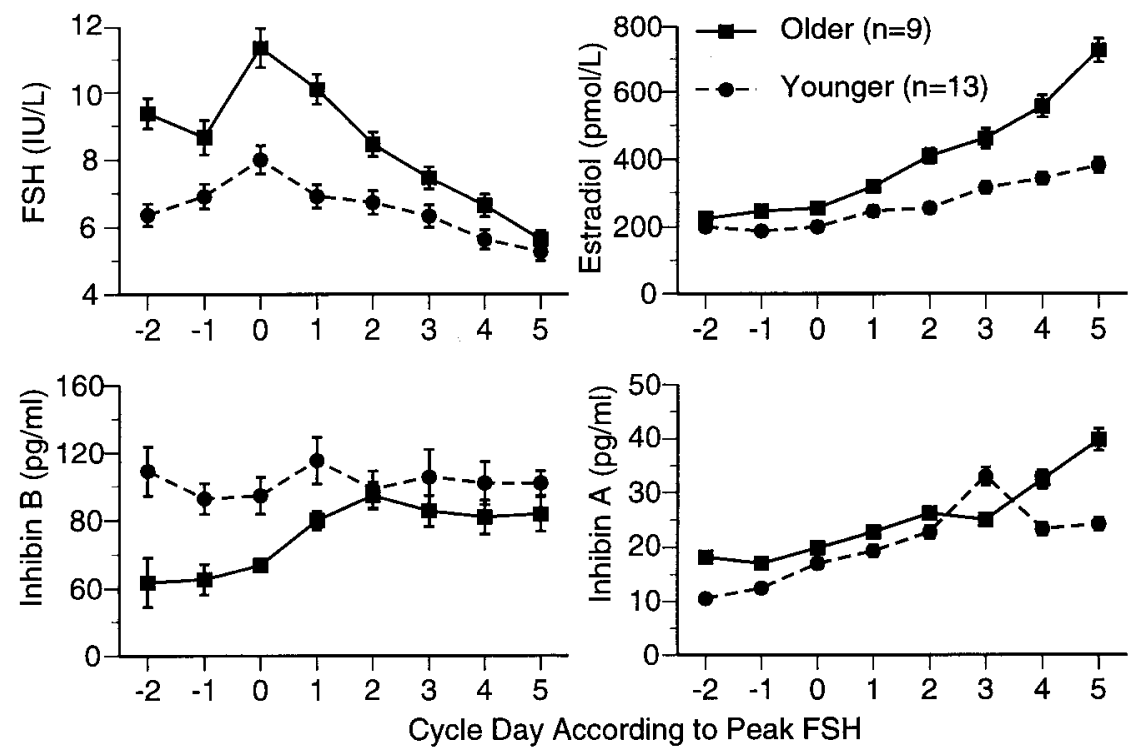

FIG. 2. Mean \pm SEM concentrations of (clockwise from top left) FSH (p $<0.01), \mathrm{E}_{2}(\mathrm{p}<$ $0.01)$, inhibin $\mathrm{A}(\mathrm{p}=0.61)$, and inhibin $\mathrm{B}(\mathrm{p}=0.04)$, according to the day of maximal FSH concentration (peak FSH = day 0). [Reprinted with permission from Klein NA, Illingworth PJ, Groome NP, McNeilly AS, Battaglia DE, Soules MR 1996 Decreased inhibin B secretion is associated with the monotropic rise of FSH in older, ovulatory women: a study of serum and follicular fluid levels of dimeric inhibin A and B in spontaneous menstrual cycles. J Clin Endocrinol Metab 81:2742-2745. Copyright The Endocrine Society.] 


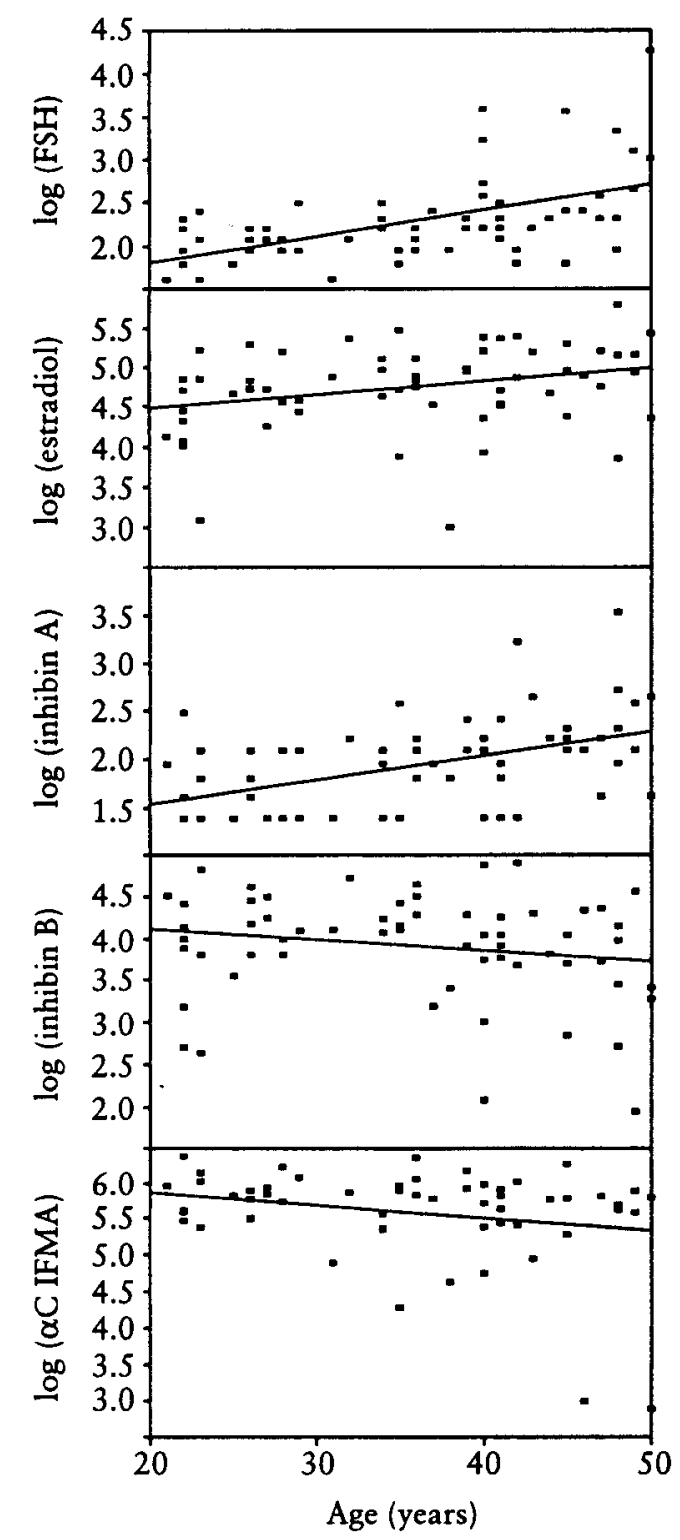

FIG. 3. Log-transformed concentrations of serum FSH, estradiol, inhibin A, inhibin B, and $\alpha$-subunit immunoactivity as functions of age $(n=59-63)$. C-terminal segment of $\alpha$ subunit; IFMA, immunofluorometric assay. [Reprinted with permission from Burger HG, Dudley EC, Mamers P, Groome N, Robertson DM 2000 Early follicular phase serum FSH as a function of age:the roles of inhibin B, inhibin A and estradiol. Climacteric 3:17-24. Copyright Parthenon Publishing Group.] 


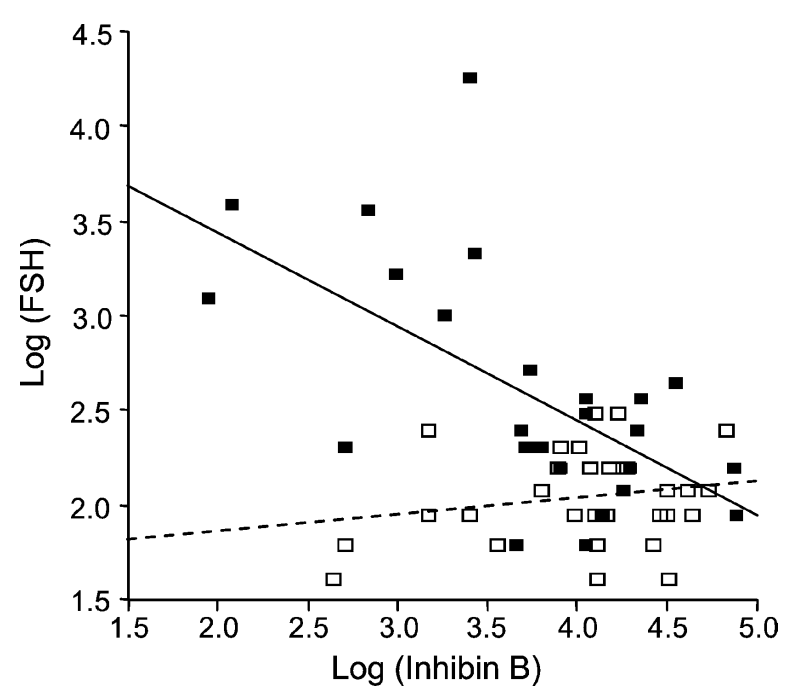

FIG. 4. Relationships between $\log (\mathrm{FSH})$ and $\log$ (inhibin B) in two age groups, 20-39 years ( $\square$ ) and 40-50 years $(\square)$. There was no significant correlation between the two hormones in the younger age group ( $r=0.19$, not significant) (dashed line) but, in the 40- to 50-year group, there was a significant inverse correlation $(r=-0.61, p<0.0001)$ solid line. FSH, follicle-stimulating hormone. [Reprinted with permission from Burger HG, Dudley EC, Mamers P, Groome N, Robertson DM 2000 Early follicular phase serum FSH as a function of age:the roles of inhibin B, inhibin A and estradiol. Climacteric 3:17-24. Copyright Parthenon Publishing Group.]

particularly from the dominant follicle and the ensuing corpus luteum (Roberts $e t$ al., 1993; Groome et al., 1996). INH-B, on the other hand, is a secretory product of small antral follicles (Roberts et al., 1993; Groome et al., 1996). Its circulating concentrations may reflect the number of follicles recruited from the primordial pool, the size of which decreases with increasing age (Richardson et al., 1987). Dominant follicles of older women continue to produce adequate amounts of $\mathrm{E}_{2}$ and INH-A and may do so as a result of the differential fall in INH-B, which allows an increased drive from the elevated concentrations of FSH.

Preservation of circulating $\mathrm{E}_{2}$ concentrations until late in female reproductive life could be hypothesised to be desirable for the preservation of overall health, including vascular and bone function.

\section{Hormonal Changes in Perimenopausal Women}

\section{A. FSH AND ESTRADIOL}

The most-noteworthy characteristic of the perimenopause is significant hormonal variability. A landmark study was performed by Sherman and Koren- 
man (1975), who reported on 50 complete menstrual cycles in 37 women. Ten women, aged 18 to 30 years with a history of regular cycles, served as controls. Six cycles were examined in regularly cycling women aged 46 to 51 , in which it was noted that the follicular phase was shorter than in younger women and that $\mathrm{E}_{2}$ concentrations were significantly lower than those observed in younger women. FSH was strikingly increased throughout the cycle, despite $\mathrm{E}_{2}$ concentrations that might have been expected to suppress its secretion. Daily hormone concentrations were measured in two women, one aged 49 and one aged 50, both clearly in the menopausal transition. Two of the cycles studied were anovulatory but were characterised by increasing $\mathrm{E}_{2}$ and initially postmenopausal values of LH and FSH, which subsequently fell with the rise of $\mathrm{E}_{2}$. An anovulatory cycle was followed by a cycle that demonstrated evidence of follicular maturation.

Metcalf and colleagues $(1979,1981)$ examined the excretion of FSH, LH, estrogens, and pregnanediol in weekly urine samples collected for 14 to 87 weeks from 31 perimenopausal women aged 36 to 55 years. Their study concentrated particularly on gonadotropin changes, although wide fluctuations in estrogen excretion were noted. These authors stated that "about the only conclusion that can be made with confidence concerning pituitary-ovarian function in individual perimenopausal women, is that it is unsafe to generalize." Metcalf (1988) subsequently concluded that "in older women, a good menstrual history is probably the single most useful measure of ovarian status." Hee et al. (1993) confirmed the variability of perimenopausal $\mathrm{E}_{2}$ concentrations and added data on immunoreactive INH in a small longitudinal study of three volunteer women who had developed irregular cycles at age 45 to 46 . Abrupt decreases in $E_{2}$ and INH into the postmenopausal range were followed by values characteristic of reproductive-aged women. It was striking that, depending on when during a cycle hormone values were determined, FSH, for example, could be at normal reproductive age levels, intermediately elevated levels, or levels characteristic of the postmenopause (Figure 5).

\section{B. STUDIES INCLUDING INHIBINS}

The Melbourne Women's Midlife Health Project was based on a crosssectional survey of a randomly selected population of 2001 Melbourne women, all Australian born, aged between 45 and 55 years at the time of initial interview (Dennerstein et al., 1993). A longitudinal study of 438 women was undertaken to examine many aspects of the menopausal transition. The data from the first year of this study were subjected to cross-sectional analysis in terms of menstrual cycle history (Burger et al., 1995). Of the subjects, 27\% reported no change in menstrual frequency or flow (Group I), 23\% a change in flow with no change in frequency (Group II), 9\% a change in frequency without change in flow (Group III), and $28 \%$ a change in both frequency and flow (Group V). By the time of 


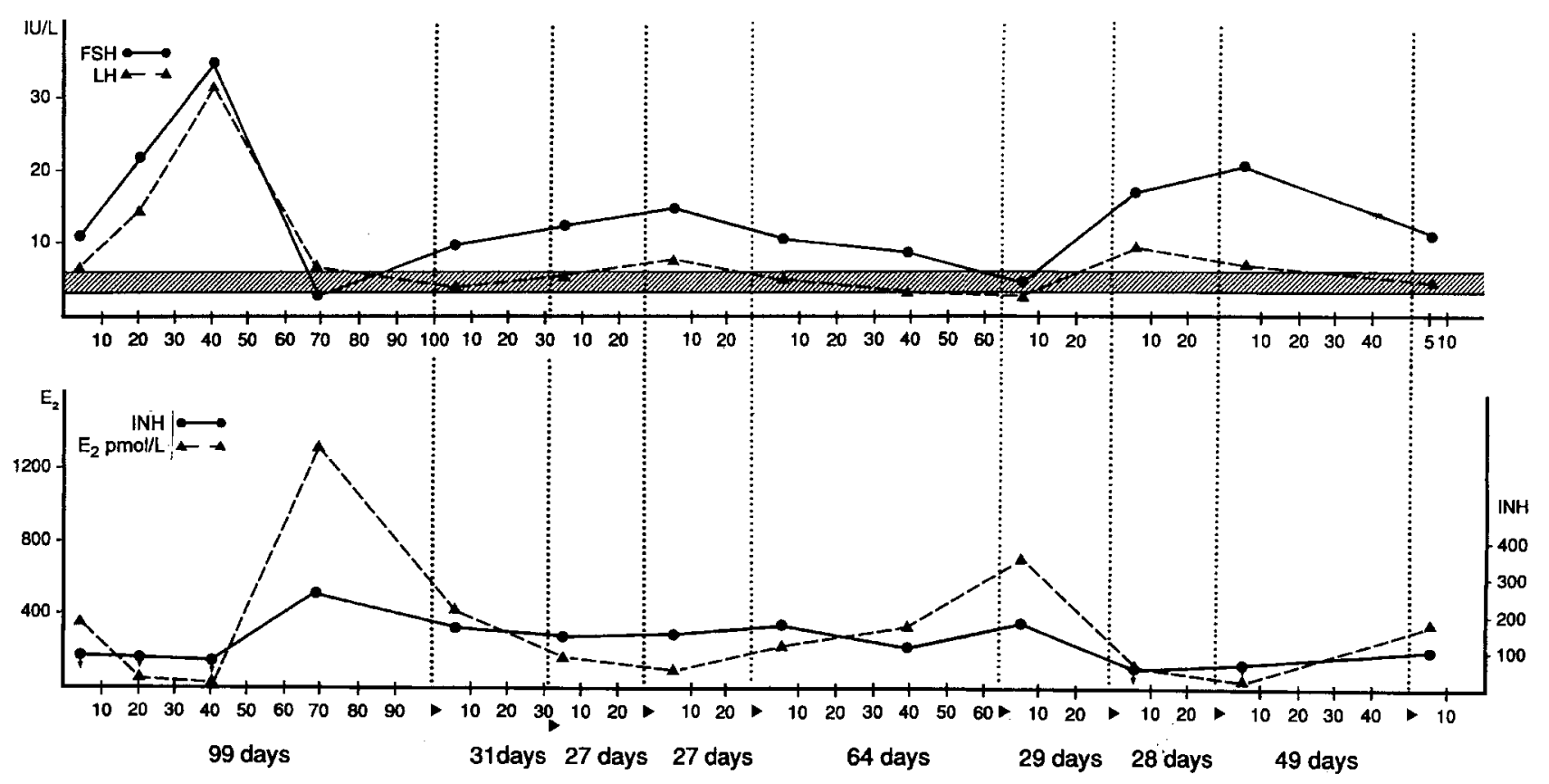

FIG. 5. Concentrations of FSH, LH, $\mathrm{E}_{2}$, and INH in a volunteer studied at the onset of the menopausal transition. The vertical dotted lines represent times of menses. The horizontal shaded bar represents the young-normal range for FSH. Note the marked fluctuations in hormone levels. [Reprinted from Hee J, MacNaughton J, Bangah M, Burger HG, Perimenopausal patterns of gonadotropins, immunoreactive inhibin, estradiol and progesterone. Maturitas 18:9-20. Copyright 1993, with permission of Elsevier Science.] 
blood sampling, $13 \%$ noted a lapse of at least 3 months since their last menstrual period. Mean age increased from 48.5 years in the first group to 51.4 in the last. Geometric mean serum FSH was similar in Groups I and II, slightly increased in Groups III and IV, and markedly increased in Group V (Figure 6). The marked variability in FSH levels between subjects in each group is noteworthy.

Although unadjusted $\mathrm{E}_{2}$ values were slightly lower in the groups experiencing a change in frequency, or those with changing frequency and flow (88 and $82 \%$ of those without any change), the only statistically significant decline in $\mathrm{E}_{2}$ occurred in those who had had no menses for at least 3 months (Group V), in whom geometric mean $\mathrm{E}_{2}$ concentration was $42 \%$ of that observed in the first group (Figure 7). After adjustment of $\mathrm{E}_{2}$ for age and body mass index (BMI), the only significant change was in the group with 3 months or more of amenorrhea, the $\mathrm{E}_{2}$ geometric mean being $54 \%$ of Group I women without change in menses. There was a very broad spread of $E_{2}$ values, some being greater than $1500 \mathrm{pmol} / \mathrm{l}$. These may reflect hyperstimulation of granulosa cells by elevated FSH levels and could give rise to symptoms of breast fullness and fluid retention.

Immunoreactive INH concentrations were significantly lower (71\% of those in the first group) in those experiencing a change in frequency and flow and had

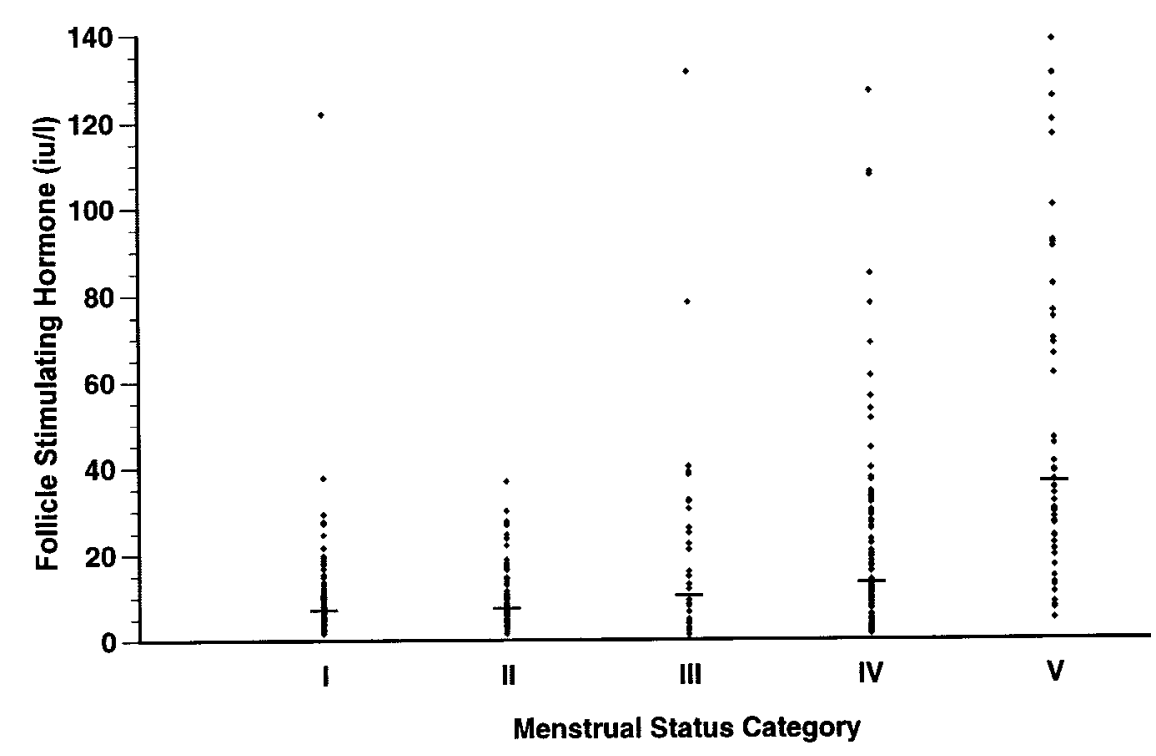

FIG. 6. Scatterplot of FSH levels versus menstrual status categories I to V. Geometric mean levels are shown by the horizontal bars. [Reprinted from Burger HG, Dudley EC, Hopper JL, Shelley JM, Green A, Smith A, Dennerstein L, Morce C 1995 The endocrinology of the menopausal transition: a cross-sectional study of a population-based sample. J Clin Endocrinol Metab 80:35373545. Copyright The Endocrine Society.] 


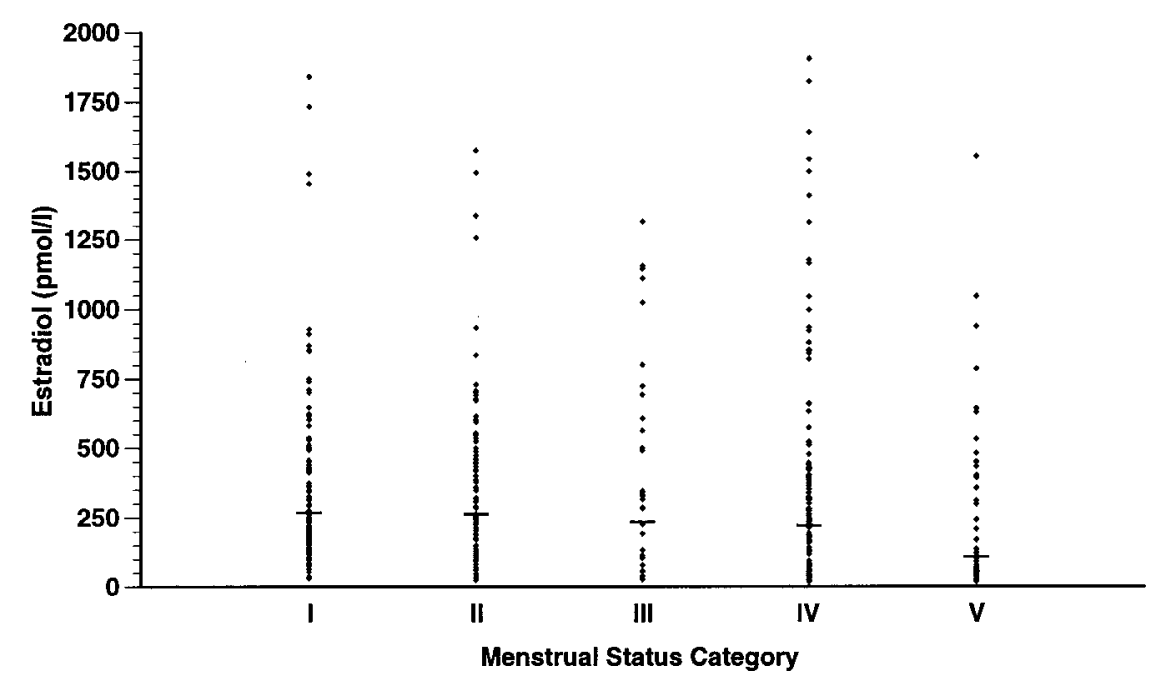

FIG. 7. Scatterplot of $E_{2}$ levels versus menstrual status categories I to V. Geometric mean levels are shown by the horizontal bars. [Reprinted with permission from Burger HG, Dudley EC, Hopper JL, Shelley JM, Green A, Smith A, Dennerstein L, Morce C 1995 The endocrinology of the menopausal transition: a cross-sectional study of a population-based sample. J Clin Endocrinol Metab 80:3537-3545. Copyright The Endocrine Society.]

fallen to $38 \%$ in those with 3 months or more of amenorrhea (Figure 8). After adjustment for age and BMI, only the change in the final group was significant, with a geometric mean $53 \%$ of that in Group I. These data suggested that decreases in inhibin occurred before decreases in $\mathrm{E}_{2}$, consistent with the hypothesis that declining concentrations of inhibin provide a mechanism for allowing FSH to rise, to maintain early follicular-phase $\mathrm{E}_{2}$ levels relatively intact.

A cross-sectional analysis of year 3 data was reported in 100 subjects aged 48 to 59 (Burger et al., 1998). Subjects were divided into those called premenopausal, without any change in menstrual cycle pattern (Group I); early perimenopausal, with a reported change in cycle frequency but experiencing menses in the preceding 3 months (Group 2); late perimenopausal, with no menses in the preceding 3-11 months (Group 3); and postmenopausal, with no menses for more than 12 months (Group 4). The hormone concentrations in the premenopausal subjects were used for reference. Early perimenopausal subjects had significantly lower levels of INH-B (13.5 ng/l, compared with $48 \mathrm{ng} / \mathrm{l})$ in the presence of a small, statistically nonsignificant rise in FSH (21.4, compared with $13.5 \mathrm{Iu} / \mathrm{l})$. There were no significant changes in $\mathrm{E}_{2}$ and $\mathrm{INH}-\mathrm{A}$. In late perimenopausal subjects, INH-A had fallen, whereas INH-B had not changed further and FSH had risen significantly to $72.2 \mathrm{Iu} / \mathrm{l}$. $\mathrm{E}_{2}$ fell to $89 \mathrm{pmol} / \mathrm{l}$ (compared with $306 \mathrm{pmol} / \mathrm{l}$ in the premenopausal group). The postmenopausal subjects showed no further 


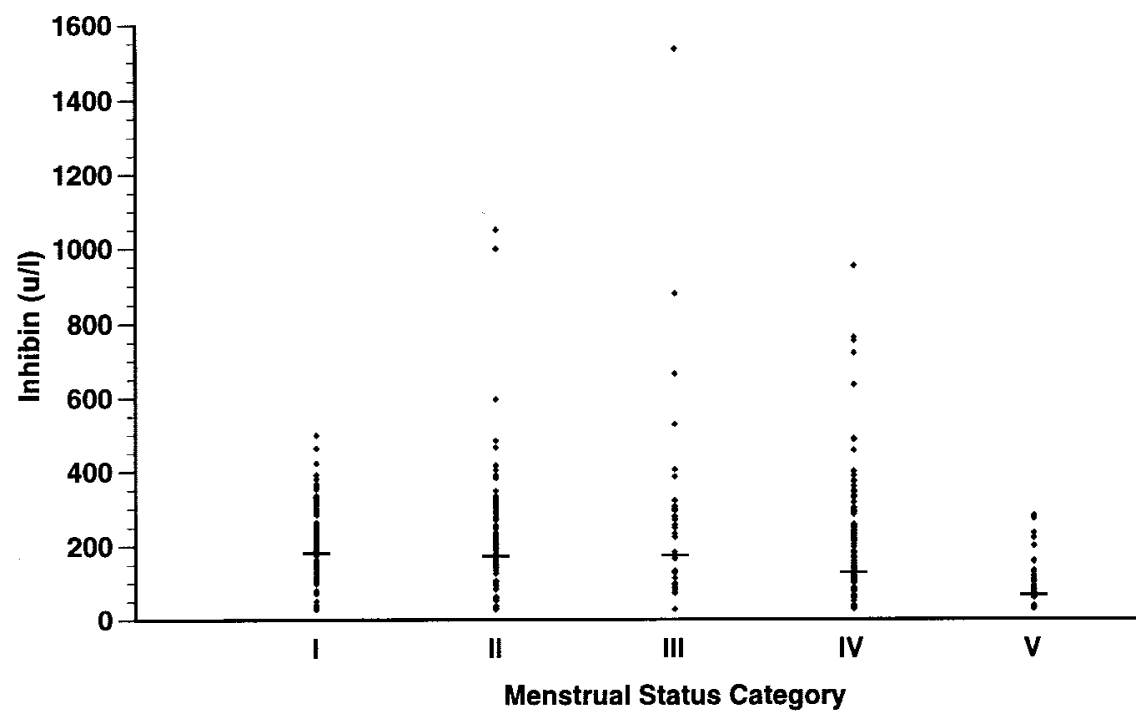

FIG. 8. Scatterplot of INH levels versus menstrual status categories I to V. Geometric mean levels are shown by the horizontal bars. [Reprinted with permission from Burger HG, Dudley EC, Hopper JL, Shelley JM, Green A, Smith A, Dennerstein L, Morce C 1995 The endocrinology of the menopausal transition: a cross-sectional study of a population-based sample. J Clin Endocrinol Metab 80:3537-3545. Copyright The Endocrine Society.]

significant changes in the peptide hormones or in $\mathrm{FSH}$. $\mathrm{E}_{2}$ fell further to 41 $\mathrm{pmol} / \mathrm{l}$ (Figure 9). There was a significant inverse correlation between FSH and $\mathrm{E}_{2}$, FSH and INH-A, and FSH and INH-B. Thus, it was concluded that the earliest endocrine change marking entry into the menopausal transition was a major fall in INH-B, presumably reflecting the attainment of a critically low number of ovarian follicles.

Overall, circulating $\mathrm{E}_{2}$ and inhibin concentrations may fluctuate widely in individual women during the menopausal transition. Grouped data show that mean changes in hormone levels become significant around the FMP, with a decrease in INH-B concentration in early perimenopausal women being the most important and significant initial endocrine event at that time. A subsequent report (Burger et al., 1999) analysed the data from the Melbourne Women's Midlife Health Project in relation to the date of final menses, rather than in relation to menstrual cycle status based on self report. It was noted that mean FSH levels began to increase starting about 2 years before FMP, increased most rapidly 10 months before FMP, and had plateaued by 2 years after FMP. $E_{2}$ levels began to decline about 2 years before FMP, decreased most rapidly around that time, and had plateaued 2 years later. There was, again, marked intersubject variability in hormone levels, 


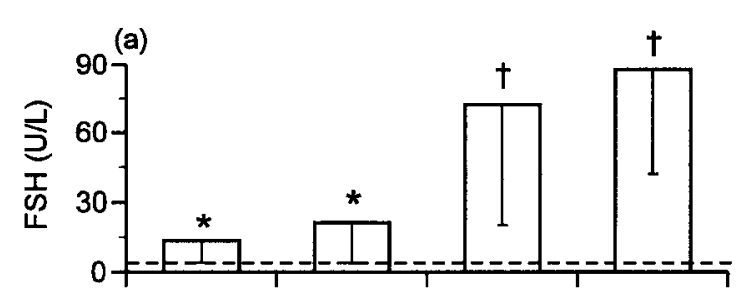

(b)

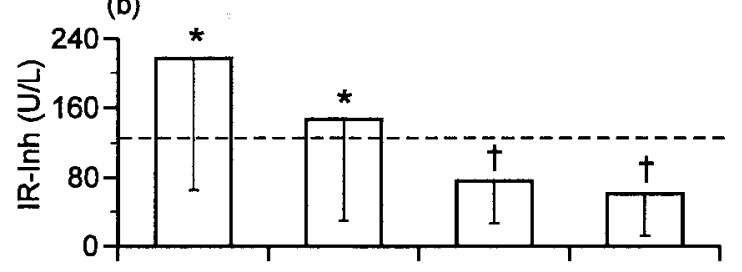

(c)

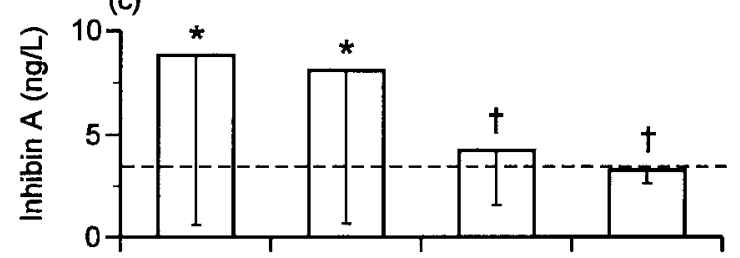

(d)

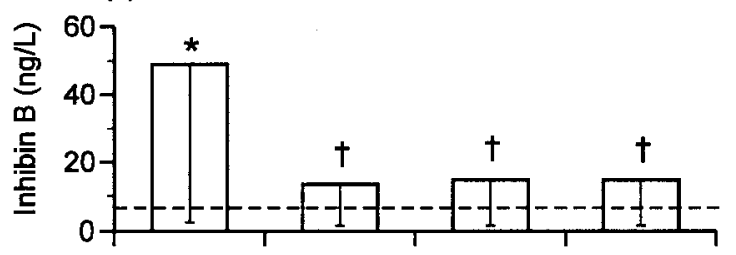

(e)

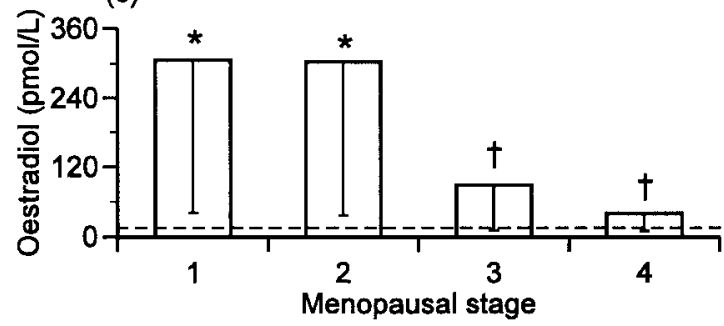

FIG. 9. Geometric mean levels (with lower 95\% confidence intervals) of (a) FSH, (b) IR-INH, (c) INH-A, (d) INH-B, and (e) $\mathrm{E}_{2}$ as a function of menopausal status. Menopausal stages are given in text. Values with the same superscript (* or $\dagger$ ) are not statistically different; values with differing superscripts differ, $\mathrm{P}<0.05$. [Reprinted with permission from Burger HG, Cahir N, Robertson DM, Groome NP, Green A, Dennerstein L 1998 Serum inhibins A and B fall differentially as FSH rises in perimenopausal women. Clin Endocrinol 48:809-813. Copyright Blackwell Science Ltd.] 
regardless of time in relation to FMP. Levels of both INH-A and INH-B decreased in the years before the FMP and were undetectable in the majority of women by the time of the FMP and almost all by 4 years post-FMP (Figure 10). The specificity and sensitivity of FSH and $\mathrm{E}_{2}$ measurements as markers of menopausal status were examined. The levels of serum FSH and $E_{2}$ at the

\section{A}

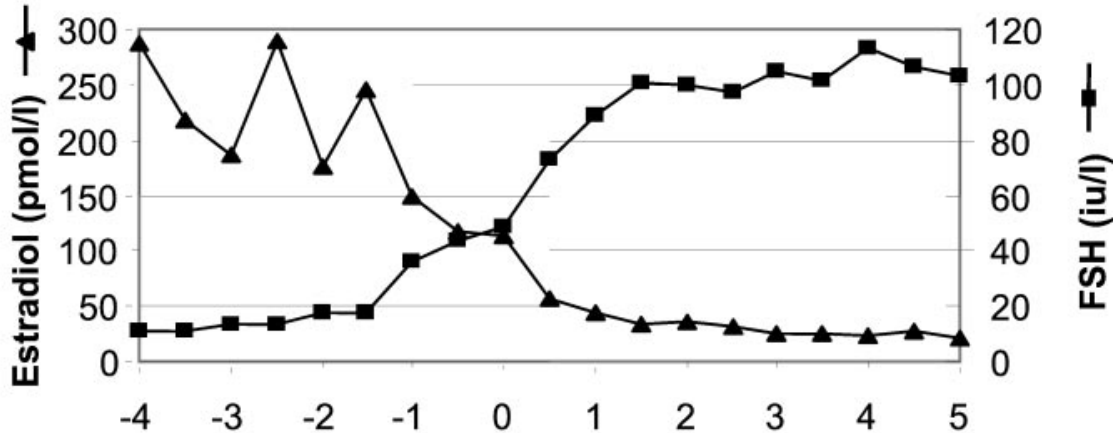

B

\section{Years around Menopause}

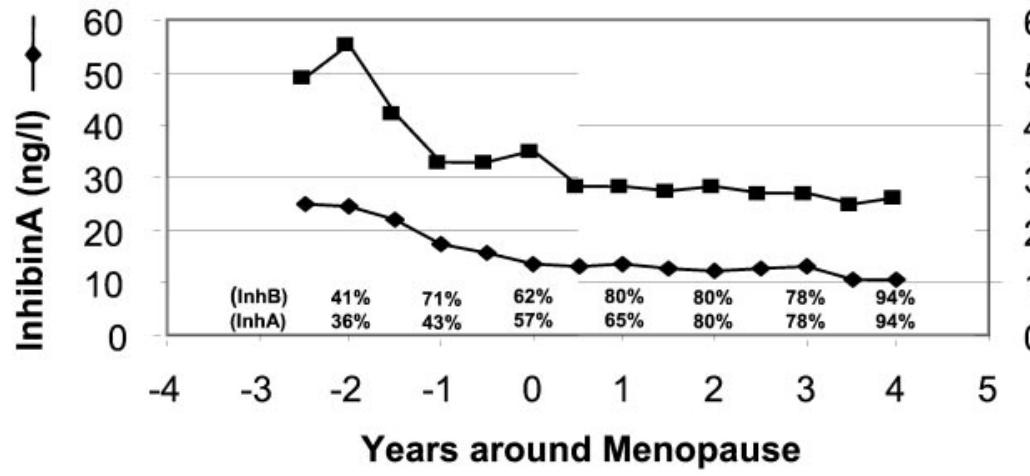

FIG. 10. Geometric means of (A) FSH and $\mathrm{E}_{2}$ and (B) INH-A and INH-B, in relation to the FMP. The horizontal axis represents time (yr) with respect to the FMP (0); negative (positive) numbers indicate time before (after) the FMP. The parentheses above the time scale (B) indicate the percentage of measured INH-A and INH-B at or below the assay sensitivity. [Reprinted with permission from Burger HG, Dudley EC, Hopper JL, Groome N, Guthrie JR, Green A, Dennerstein L 1999 Prospectively measured levels of serum FSH, estradiol and the dimeric inhibins during the menopausal transition in a population-based cohort of women. J Clin Endocrinol Metab 84:40254030. Copyright The Endocrine Society.] 
intersection of the fitted longitudinal curves for the geometric mean data with the date of final menses were calculated and found to be $108 \mathrm{Iu} / 1$ and 88.5 $\mathrm{pmol} / \mathrm{l}$, respectively. Seventy-six percent of premenopausal women had levels of FSH below this concentration and $67 \%$ had levels of $E_{2}$ above this concentration, whereas in postmenopausal women $85 \%$ had levels above that concentration of FSH and $84 \%$ levels of $\mathrm{E}_{2}$ below it.

It was concluded that substantial changes in reproductive hormone levels occurred within 1-2 years on each side of the FMP; that falling concentrations of $\mathrm{E}_{2}$ and the inhibins contribute to the rise in concentrations of FSH; and that there is no single, reliable hormonal marker of menopausal status for an individual woman.

\section{PROGESTERONE}

It is well known from studies in which basal body temperature had been used as a marker of ovulatory function that anovulatory cycles become more prevalent with increasing age. A large study of luteal-phase P concentrations (Trevoux et al., 1986) noted that the frequency of nondetectable P increased as FMP approached. The lack of a luteal-phase rise in $\mathrm{P}$ is a striking feature of the postmenopause, compared with the reproductive period. Rannevik et al. (1995) reported that the frequency of cycles with $\mathrm{P}$ values indicative of ovulation decreased from $60 \%$ to less than $10 \%$ during the 6 years preceding the FMP. Ovulatory P concentrations were found in $62.2 \%$ of women, $72-61$ months premenopausal and in $4.8 \%$ who were 6-0 months premenopausal, whereas all serum $\mathrm{P}$ measurements were less than $2 \mathrm{nmol} / \mathrm{l}$ postmenopausally.

\section{ANDROGENS}

Variable findings have been reported in regard to the change in circulating androgens in relation to the FMP. Rannevik et al. (1995) reported a small but significant decline in testosterone (T), androstenedione (A), and sex hormone-binding globulin (SHBG) during the 2 years around menopause. Longcope et al. (1986) did not see any change in T and A over 80 months from FMP but noted that the mean concentrations of $\mathrm{T}$ in all their subjects, including those still having cyclic menses, were significantly less than those of a group of normal young women sampled on days 5-7 of the cycle. They suggested that there is a decrease in the ovarian secretion of $\mathrm{T}$ prior to menopause. Zumoff et al. (1995), in fact, found that there was a steep decline in total serum $\mathrm{T}$ with age, such that levels in a woman aged 40 were approximately $50 \%$ of those in a woman aged 21 . Free $\mathrm{T}$ concentrations showed a similar decline. Other studies have suggested that total $\mathrm{T}$ levels decrease by approximately $20 \%$ and A by approximately $50 \%$ with natural menopause (Judd, 1976). Vermeulen et al. (1976) showed that postmeno- 
pausal women aged 51 to 65 years had lower mean levels of $\mathrm{T}, \mathrm{A}$, and dihydrotestosterone (DHT) than women aged 18 to 25 , not inconsistent with the observation of Zumoff et al. (1995).

In the Melbourne Women's Midlife Health Project, there was no significant change seen in total $\mathrm{T}$ or in the T:SHBG ratio (the free androgen index, FAI) as a function of changing menopausal status when assessed crosssectionally (Burger et al., 1995). More recently, serum androgen levels have been reported in relation to final menses using longitudinal data from the same project (Burger et al., 2000a). Mean T levels did not vary with time relative to FMP and were independent of age and BMI. FAI increased by $80 \%$ from 4 years before FMP to 2 years after because of a concomitant decrease in SHBG levels across this time period (Figures 11-13). DHEAS levels were not related to FMP but declined slowly with age. It was concluded that SHBG and FAI levels change at the time of menopause, at least partially due to the decline in $\mathrm{E}_{2}$. DHEAS decreases as a function of age but not relative to FMP. $\mathrm{T}$ remained unchanged through the menopausal transition and the early postmenopause.

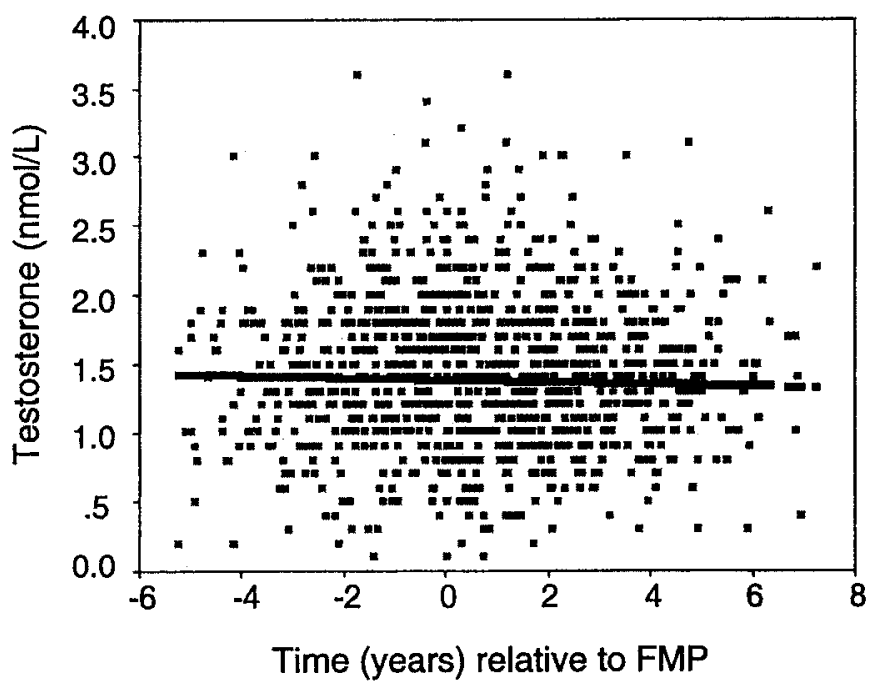

FIG. 11. Linear regression model: observed $\mathrm{T}$ and fitted levels of mean $\mathrm{T}$ across the menopausal transition. The horizontal axis represents time (years) with respect to FMP (0); negative (positive) numbers indicate time before (after) FMP. [Reprinted with permission from Burger HG, Dudley EC, Cui J, Dennerstein L, Hopper JL 2000 A prospective longitudinal study of serum testosterone dehydroepiandrosterone sulphate and sex hormone binding globulin levels through the menopause transition. J Clin Endocrinol Metab 85:2832-2938. Copyright The Endocrine Society.] 


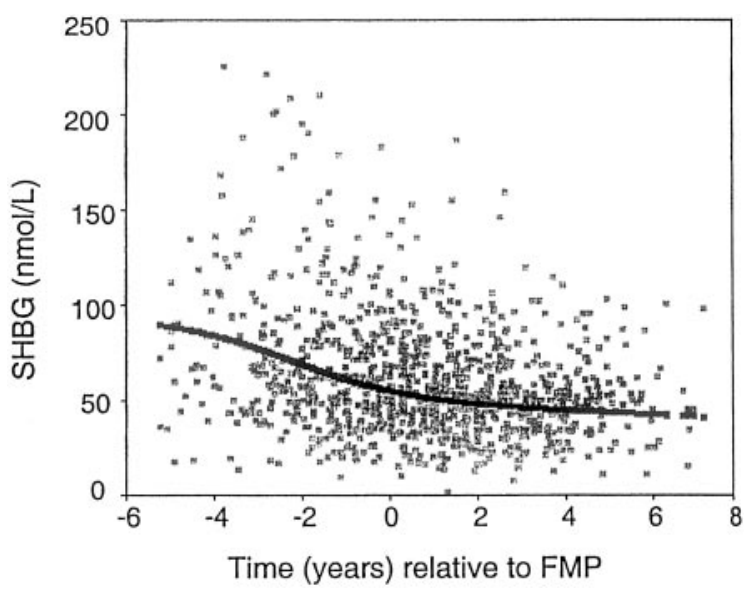

FIG. 12. Double logistic model: observed SHBG and fitted levels of mean SHBG across the menopausal transition. The horizontal axis represents time (years) with respect to FMP (0); negative (positive) numbers indicate time before (after) FMP. [Reprinted with permission from Burger HG, Dudley EC, Cui J, Dennerstein L, Hopper JL 2000 A prospective longitudinal study of serum testosterone dehydroepiandrosterone sulphate and sex hormone binding globulin levels through the menopause transition. J Clin Endocrinol Metab 85:2832-2938. Copyright The Endocrine Society.]

\section{Conclusions}

The perimenopause is a time of markedly fluctuating hormone levels. Attempts to define menopausal status purely on the basis of single measurements of FSH or $\mathrm{E}_{2}$ are unlikely to yield useful information. Though $\mathrm{E}_{2}$ concentrations appear to be preserved in regularly cycling women, at least until around age 50, INH-B declines and FSH rises. The establishment of menstrual irregularity is marked by a decrease in follicular-phase concentrations of INH-B, an increase in FSH, but relative preservation of $\mathrm{E}_{2}$ and INH-A until FMP. The frequency of anovulatory cycles increases markedly as FMP approaches. It is difficult to demonstrate substantial changes in androgen concentrations in the immediate perimenopausal period, though levels postmenopausally appear to be lower than those of young, regularly cycling women, perhaps as a function of increasing age during the reproductive years rather than menopausal status. Hormonal measurements are of little diagnostic value during the perimenopause, other than for purposes of physiological study. The issue of the appropriate reference points for the study of the perimenopause remains unclear, although the staging system adopted in the Melbourne Women's Mid-Life Health Project appears to be potentially useful because of the clear-cut hormonal (and symptomatic) differences between early and late perimenopausal women. 


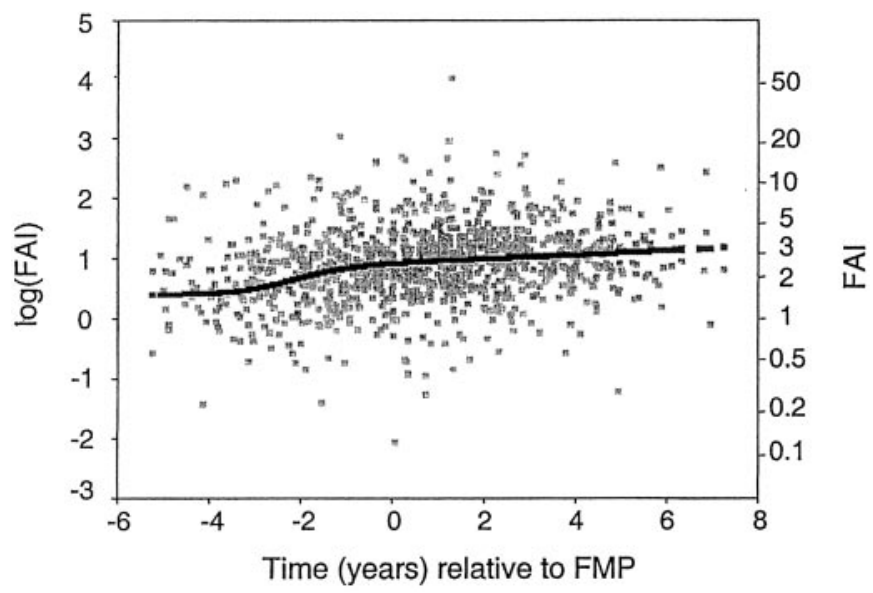

FIG. 13. Double logistic model: observed FAI and fitted levels of mean FAI across the menopausal transition. The left and right axes show FAI levels on the $\log$ and antilog scales, respectively. The horizontal axis represents time (years) with respect to FMP (0); negative (positive) numbers indicate time before (after) FMP. [Reprinted with permission from Burger HG, Dudley EC, Cui J, Dennerstein L, Hopper JL 2000 A prospective longitudinal study of serum testosterone dehydroepiandrosterone sulphate and sex hormone binding globulin levels through the menopause transition. J Clin Endocrinol Metab 85:2832-2938. Copyright The Endocrine Society.]

\section{ACKNOWLEDGMENTS}

The authors acknowledge with gratitude grants received from the Victorian Health Promotion Foundation and the National Health and Medical Research Council. Support for hormone assays was provided by an unrestricted grant from Organon (Australia) Pty Ltd. The assistance of Mr. N. Balazs from the Monash Medical Centre, Department of Chemical Pathology, for gonadotropin and steroid assays is gratefully recognised. Professor Nigel Groome (Oxford Brookes University, Oxford, U.K.) generously provided reagents for inhibin A and B assays. We thank Mrs. Sue Elger and Ms. Sue Panckridge for their assistance in preparing the manuscript.

\section{REFERENCES}

Burger HG, Dudley EC, Hopper JL, Shelley JM, Green A, Smith A, Dennerstein L, Morce C 1995 The endocrinology of the menopausal transition: a cross-sectional study of a populationbased sample. J Clin Endocrinol Metab 80:3537-3545

Burger HG, Cahir N, Robertson DM, Groome NP, Green A, Dennerstein L 1998 Serum inhibins $\mathrm{A}$ and $\mathrm{B}$ fall differentially as FSH rises in perimenopausal women. Clin Endocrinol 48:809-813

Burger HG, Dudley EC, Hopper JL, Groome N, Guthrie JR, Green A, Dennerstein L 1999 Prospectively measured levels of serum FSH, estradiol and the dimeric inhibins during the menopausal transition in a population-based cohort of women. J Clin Endocrinol Metab 84:4025-4030 
Burger HG, Dudley EC, Cui J, Dennerstein L, Hopper JL 2000a A prospective longitudinal study of serum testosterone dehydroepiandrosterone sulphate and sex hormone binding globulin levels through the menopause transition. J Clin Endocrinol Metab 85:2832-2938

Burger HG, Dudley EC, Cui J, Mamers P, Groome N, Robertson DM 2000b Early follicular phase serum FSH as a function of age:the roles of inhibin B, inhibin A and estradiol. Climacteric 3:17-24

Dennerstein L, Smith AM, Morse C, Burger HG, Green A, Hopper J, Ryan M 1993 Menopausal symptomatology: the experience of Australian women. Med J Aust 159:232-236

Groome NP, Illingworth PJ, O'Brien M, Rodger PAL, Rodger FE, Mather JF, McNeilly AS 1996 Measurement of dimeric inhibin B throughout the human menstrual cycle. J Clin Endocrinol Metab 81:1401-1405

Hee J, MacNaughton J, Bangah M, Burger HG 1993 Perimenopausal patterns of gonadotrophins, immunoreactive inhibin, estradiol and progesterone. Maturitas 18:9-20

Judd HL 1976 Hormonal dynamics associated with the menopause. Clin Obstet Gynecol 19:775-788

Klein NA, Illingworth PJ, Groome NP, McNeilly AS, Battaglia DE, Soules MR 1996 Decreased inhibin B secretion is associated with the monotropic rise of FSH in older, ovulatory women: a study of serum and follicular fluid levels of dimeric inhibin A and B in spontaneous menstrual cycles. J Clin Endocrinol Metab 81:2742-2745

Lee SJ, Lenton EA, Sexton L, Cooke ID 1988 The effect of age on the cyclical patterns of plasma LH, FSH, estradiol and progesterone in women with regular menstrual cycles. Hum Reprod 3:851-855

Longcope C, Franz C, Morello C, Baker R, Johnston C Jr 1986 Steroid and gonadotropin levels in women during the perimenopausal years. Maturitas 8:189-196

MacNaughton J, Bangah M, McCloud P, Hee J, Burger HG 1992 Age related changes in follicle stimulating hormone, luteinizing hormone, estradiol and immunoreactive inhibin in women of reproductive age. Clin Endocrinol 36:339-345

McKinlay SM, Brambilla DJ, Posner JG 1992 The normal menopausal transition. Maturitas 14:103-115

Metcalf MG 1988 The approach of menopause: a New Zealand Study. NZ Med J 101:103-106

Metcalf MG, Donald RA 1979 Fluctuating ovarian function in a permenopausal woman. NZ Med J 89:45-47

Metcalf, MG, Donald RA, Livesey JH 1981 Pituitary ovarian function in normal women during the menopausal transition. Clin Endocrinol 14:234-255

Rannevik G, Caristrom K, Jeppsson S, Bjerre B, Svanberg L 1986 A prospective long-term study in women from premenopause to postmenopause: changing profiles of gonadotrophins, oestrogens and androgens. Maturitas 8:297-307

Rannevik G, Jeppsson S, Johnell O, Bjerre B, Laurell-Boruli Y, Svanberg L 1995 A longitudinal study of the perimenopausal transition: altered profiles of steroid and pituitary hormones, SHBG and bone mineral density. Maturitas 21:103-113

Richardson SJ, Senikas V, Nelson JF 1987 Follicular depletion during the menopausal transition: evidence for accelerated loss and ultimate exhaustion. J Clin Endocrinol Metab 65:1231-1237

Roberts VJ, Barth S, El-Roeiy A, Yen SSC 1993 Expression of inhibin/activin subunits and follistatin messenger ribonucleic acids and proteins in ovarian follicles and the corpus luteum during the human menstrual cycle. J Clin Endocrinol Metab 77:1402-1410

Santoro N, Brown JR, Adel T, Skurnick JH 1996 Characterization of reproductive hormonal dynamics in the perimenopause. J Clin Endocrinol Metab 81:1495-1501

Sherman BM, Korenman SG 1975 Hormonal chacteristics of the human menstrual cycle throughout reproductive life. J Clin Invest 55:699-706 
Sherman BM, West JH, Korenman SG 1976 The menopausal transition: analysis of LH, FSH, estradiol, and progesterone concentrations during menstrual cycles of older women. J Clin Endocrinol Metab 42:629-636

Treloar AE 1981 Menstrual cyclicity and the pre-menopause. Maturitas 3:249-264

Trevoux R, De Brux J, Castanier M, Nahoul K, Soule J-P, Scholler R 1986 Endometrium and plasma hormone profile in the peri-menopause and postmenopause. Maturitas 8:309-326

Vermeulen A 1976 The hormonal activity of the postmenopausal ovary. J Clin Endocrinol Metab 42:247-253

World Health Organization 1996 Research on the Menopause in the 1990s. Technical report Scr 866, Geneva, Switzerland

Zumoff B, Strain GW, Miller LK, Rosner W 1995 Twenty-four hour mean plasma testosterone concentration declines with age in normal premenopausal women. J Clin Endocrinol Metab 80:1429-1430 